\title{
Quality of life in patients with chronic alveolar hypoventilation
}

\author{
C. Dellborg*, J. Olofson*, B. Midgren\#, O. Caro", B-E. Skoogh*, M. Sullivan ${ }^{+}$
}

\begin{abstract}
Quality of life in patients with chronic alveolar hypoventilation. C. Dellborg, J. Olofson, B. Midgren, O. Caro, B-E. Skoogh, M. Sullivan. (C)ERS Journals Ltd 2002.

ABSTRACT: Measurements of health-related quality of life (HRQL) have not been reported in patients with chronic alveolar hypoventilation (CAH) before starting home mechanical ventilation. The purpose of this study was to investigate quality of life in a population of such patients.

Forty-four consecutive patients with $\mathrm{CAH}$ due to previous polio, scoliosis, healed pulmonary tuberculosis or neuromuscular disease answered a battery of condition specific and generic (Sickness Impact Profile, Hospital Anxiety and Depression scale, Mood Adjective Check List) self-report questionnaires. Spirometry, arterial blood gases and overnight oxygen saturation were measured.

Patients with untreated CAH had significantly impaired HRQL compared to historical data from a healthy reference population. Sleep-related problems were frequent. Age, underlying disease, and standard bicarbonate correlated significantly with HRQL measures, albeit with modest levels of explained variance (8-37\%).

Patients with chronic alveolar hypoventilation due to neuromuscular or restrictive chest wall disorders had severely impaired health-related quality of life. Age, the underlying disease and severity of hypoventilation are each related to the health-related quality of life decrements. Health-related quality of life measurements add important information to traditional clinical observations.
\end{abstract}

Eur Respir J 2002; 19: 113-120.

\begin{abstract}
*Dept of Respiratory Medicine and Allergology, Sahlgrenska University Hospital, Göteborg, \#Dept of Respiratory Medicine, University Hospital of Lund, "Dept of Respiratory Medicine, Örebro Medical Center Hospital, Örebro, and ${ }^{+}$Health Care Research Unit, Dept of Internal Medicine, Sahlgrenska University Hospital, Göteborg, Sweden.
\end{abstract}

Correspondence: M. Sullivan, Health Care Research Unit, Sahlgrenska University Hospital, SE 41345 Göteborg, Sweden. Fax: 4631826941

Keywords: Chronic alveolar hypoventilation, neuromuscular and restrictive chest wall disorders, quality of life

Received: February 52001

Accepted after revision July 62001

This study was supported by grants from the Swedish Heart-Lung Foundation and from the Medical Faculty, Göteborg University.
Chronic alveolar hypoventilation $(\mathrm{CAH})$, caused by neuromuscular or restrictive chest wall disorders is usually most marked during sleep [1]. The predominant symptoms are disturbed sleep, tiredness, morning headache and breathlessness [1]. Noninvasive home mechanical ventilation is effective in providing nocturnal ventilatory support in these patients, with improvement in blood gases and relief of symptoms [2-4].

In recent years, increasing interest in health related quality of life (HRQL) measurements has provided information on the impact of chronic diseases on functioning and wellbeing [5-8]. Several instruments with satisfactory reliability, validity, interpretability and responsiveness are frequently used in clinical studies of diseases where impairments are incurable or insufficiently understood and where the realistic goal of care is to make patients' lives as comfortable, functional and satisfying as possible [9]. Generic instruments such as the Sickness Impact Profile (SIP) [10] have been shown to be sensitive enough to identify specific dysfunction profiles in several clinical conditions [11-14].

The few reports concerning HRQL in patients with $\mathrm{CAH}$ due to neuromuscular or restrictive chest-wall disorders focus on patients already receiving treatment $[15,16]$ and give little information about the effects of CAH per se on HRQL. Thus, there is a need for more information about the degree of dysfunction and consequent reduction of various aspects of quality of life in patients suffering from $\mathrm{CAH}$.

The aim of this study was to investigate consecutive patients with untreated $\mathrm{CAH}$ due to neuromuscular or restrictive chest-wall disorders to: 1) describe their HRQL; 2) explore any differences in HRQL among the different diagnostic groups; and 3) correlate the HRQL results with clinical observations and measurements.

\section{Material and methods}

The study was approved by the Committee for Medical Research Ethics at Göteborg University. All participants gave written informed consent.

\section{Study subjects}

The study group comprised consecutive patients ( $>16$ yrs) living in the western part of Sweden $(\sim 1.5$ million inhabitants), Lund ( 700,000 inhabitants) and Örebro ( 275,000 inhabitants). They were recruited over a 3-yr period (1992-1995) from patients referred to the Dept of Pulmonary Medicine for evaluation of hypoventilation due to neuromuscular disorders, 
Table 1.-Age, lung function and blood gases in patients with chronic alveolar hypoventilation

\begin{tabular}{|c|c|c|c|c|}
\hline & All patients & Scoliosis & Previous polio & TB sequelae \\
\hline Subjects $n$ & 44 & 11 & 12 & 17 \\
\hline Male \% & 46 & 36 & 42 & 41 \\
\hline Age yrs & $61(12.5)$ & $59(14.3)$ & $58(8.3)$ & $67(7.0)$ \\
\hline VC L & $1.2(0.4)$ & $1.0(0.3)$ & $1.3(0.5)$ & $1.2(0.4)$ \\
\hline FEV1 L & $0.8(0.35)$ & $0.7(0.3)$ & $1.0(0.4)$ & $0.7(0.25)$ \\
\hline Daytime $\mathrm{Pa}, \mathrm{CO}_{2} \mathrm{kPa}$ & $7.3(0.85)$ & $7.0(0.65)$ & $7.0(0.95)$ & $7.6(0.8)$ \\
\hline Daytime $\mathrm{Pa}, \mathrm{O}_{2} \mathrm{kPa}$ & $8.1(1.4)$ & $8.0(1.5)$ & $8.3(1.3)$ & $7.9(1.3)$ \\
\hline Standard bicarbonate $\mathrm{mmol} \cdot \mathrm{L}^{-1}$ & $30.5(2.3)$ & $30.0(1.8)$ & $30.0(1.4)$ & $31.5(2.7)$ \\
\hline Mean nocturnal $S_{\mathrm{a}, \mathrm{O}_{2}} \%$ & $87(5.9)$ & $85(6.2)$ & $87(6.2)$ & $88(6.0)$ \\
\hline Morning $\mathrm{Pa}_{2} \mathrm{CO}_{2} \mathrm{kPa}$ & $8.1(1.0)$ & $7.8(0.9)$ & $7.9(1.15)$ & $8.2(1.1)$ \\
\hline
\end{tabular}

Data are presented as mean and standard deviation for all patients and for the major diagnostic groups. Diagnoses for patients not included above; Diaphragm weakness (1), Ankylosing spondylits (1), muscular dystrophy (2). TB: tuberculosis; VC: vital capacity; FEV1: forced expiratory volume in 1 second; $\mathrm{Pa}_{\mathrm{a}} \mathrm{CO}_{2}: \mathrm{CO}_{2}$ tension in arterial blood; $\mathrm{Pa}, \mathrm{O}_{2}: \mathrm{O}_{2}$ tension in arterial blood; $\mathrm{Sa}_{\mathrm{a}} \mathrm{O}_{2}$ : arterial oxygen saturation.

previous polio, sequelae of healed pulmonary tuberculosis (TB) sequelae, scoliosis or other thoracic deformity. Patients were included if the following criteria were met: 1) Chronic alveolar hypoventilation $\left(\geqslant 2\right.$ observations of daytime arterial $\mathrm{CO}_{2}$ tension in arterial blood $\left.\left.\left(P \mathrm{a}, \mathrm{CO}_{2}\right) \geqslant 6.2 \mathrm{kPa}\right) ; 2\right)$ stable clinical condition for 3 weeks prior to the investigation; 3) presumed ability to handle home mechanical ventilation; 4) informed consent.

Of 58 consecutive patients, 44 fulfilled these criteria. Their mean \pm SD age was $63 \pm 10.0$ yrs. Eleven patients had scoliosis, 12 previous polio, $17 \mathrm{~TB}$ sequelae, 2 muscular dystrophy, one ankylosing spondylitis and one diaphragm weakness (table 1). Twelve patients were receiving long-term oxygen treatment when they entered the study. Five patients were wheel-chair dependent.

Fourteen of the initially referred patients were not included in the study; four were in an unstable clinical condition or were receiving invasive ventilatory support, two had none of the relevant underlying diagnoses, three proved not to have $P \mathrm{a}, \mathrm{CO}_{2} \geqslant 6.2 \mathrm{kPa}$, four were judged not to be able to handle home mechanical ventilation and one was missed due to logistical reasons.

\section{Physiological measurements}

Arterial blood gases. One sample was obtained from the radial artery after $30 \mathrm{~min}$ of rest in the supine position in the afternoon. One sample was also obtained in the morning before subjects left their beds. Measurements were made using Radiometer ABL2 (Radiometer, Copenhagen, Denmark). Measurement of oxygen saturation $\left(\mathrm{Sa}_{\mathrm{a}} \mathrm{O}_{2}\right)$ during the night was made by pulse oximetry (Ohmeda Oxymeter 3700, Louisville, KT, USA). The mean $\mathrm{Sa}_{\mathrm{a}} \mathrm{O}_{2}$ was calculated electronically. Spirometry (slow vital capacity) was performed according to the guidelines of the European Respiratory Society [17].

Social life. Patients were asked about their marital status, economic status, employment and satisfaction with social life.
Health-related quality of life measures. A set of selfreport HRQL questionnaires were used according to a conceptual and measurement model (table 2) with the

Table 2. - Proposed conceptual and measurement model of health related quality of life in chronic alveolar hypoventilation. Modified from SULLIVAN et al [9]

\begin{tabular}{|c|c|}
\hline Concepts & Instruments \\
\hline $\begin{array}{l}\text { Disease-related } \\
\text { and generic }\end{array}$ & $\begin{array}{l}\text { Respiratory, sleep } \\
\text { oriented and generic }\end{array}$ \\
\hline $\begin{array}{l}\text { Condition-specific } \\
\text { Complaints/ } \\
\text { consequences }\end{array}$ & $\begin{array}{l}\text { MRC } \\
\text { Breathlessness } \\
\text { Sleep-related problems } \\
\text { Sleep disturbances } \\
\text { Daytime hypersomnolence } \\
\text { Morning headache }\end{array}$ \\
\hline $\begin{array}{l}\text { Generic: functional health } \\
\text { Physical/ mobility } \\
\text { oriented consequences }\end{array}$ & $\begin{array}{l}\text { SIP } \\
\text { Overall } \\
\text { Physical dimension } \\
\text { Ambulation, Mobility, } \\
\text { Body care/ movement, } \\
\text { Sleep/ rest, Home } \\
\text { management, Work, } \\
\text { Recreation/ } \\
\text { pastimes, Eating }\end{array}$ \\
\hline $\begin{array}{l}\text { Social/ emotional/ } \\
\text { cognitive consequences }\end{array}$ & $\begin{array}{l}\text { SIP } \\
\text { Psychosocial dimension } \\
\text { Social interaction, } \\
\text { Emotional behaviour, } \\
\text { Alertness behaviour, } \\
\text { Communication }\end{array}$ \\
\hline $\begin{array}{l}\text { Generic: Mental health } \\
\text { Distress/ well-being }\end{array}$ & $\begin{array}{l}\text { HAD } \\
\text { Depression } \\
\text { Anxiety } \\
\text { MACL } \\
\text { Overall } \\
\text { Pleasantness/ } \\
\text { unpleasantness } \\
\text { Activation/ deactivation } \\
\text { Calmness/ tension }\end{array}$ \\
\hline Overall quality of life & Global rating \\
\hline
\end{tabular}

MRC: Medical Research Council; SIP: Sickness Impact Profile; HAD: Hospital Anxiety and Depression scale; MACL: Mood Adjective Check List. 
instruments ordered along a continuum of concepts from condition-specific through functional health and mental wellbeing to overall quality of life [9]. The generic questionnaires are well known, have high validity and reliability and have been used in several studies of HRQL [11-15, 18, 19]. The patients answered the questionnaires assisted by a research nurse.

Breathlessness. Breathlessness was evaluated using four questions from part of the widely used Medical Research Council questionnaire [20]. The questions had a yes/no response format and provided a scale from $1-5$ to reflect the degree of disability. Patients were also asked if they were breathless at rest.

Sleep-related problems. An 18-item questionnaire on sleep quality and related problems was included which has been developed and used in a Swedish stress research programme [21]. In this instrument a four point categorical scale indicates degrees of severity: never/almost never, sometimes, once a week and always/almost always. A sleep scale with satisfactory reliability that was created in an earlier study was also used [15]. This contains three items: difficulty in initiating sleep, difficulty in maintaining sleep and irregular sleep, with high scores indicating problems.

Functional health. Functional status was measured by the Swedish version [18] of the Sickness Impact Profile (SIP) [10], which describes the patients' overall health status. It contains 136 items grouped into 12 categories (table 3). The SIP includes calculation of physical and psychosocial dimension scores and an overall aggregation of the 12 categories (Overall SIP score). Each item deals with a specified dysfunction. Respondents are requested to mark only those items that describe limitations experienced today in relation to their health. Scores for 12 categories, two dimensions and the overall SIP are calculated from item weights, and expressed as the percentage of maximum dysfunction to form a scale of $0-100$. Thus, high scores indicate dysfunction. A cut-off point $>10$ was applied for severe dysfunction [22].

Mental health. The Hospital Anxiety and Depression scale (HAD) was used to detect psychiatric morbidity [23]. It consists of 14 items on a four-point scale and gives separate scores for anxiety and depression. Scores $<8$ indicate no clinical distress, scores of 8-10 indicate possible psychiatric morbidity and scores $>10$ probable pathological levels of distress. It has previously been adapted to Swedish conditions [19].

The Mood Adjective Check List (MACL) measures emotional states and mental wellbeing [24]. The short form of the 71-item questionnaire contains 38 items categorized into three dimensions (table 3). Each

Table 3. - Mean scores from The Sickness Impact Profile (SIP), The Hospital Anxiety and Depression scale (HAD) and The Mood Adjective Check List (MACL) for the study sample, a healthy reference population and patients with severe chronic obstructive pulmonary disease (COPD)

\begin{tabular}{|c|c|c|c|}
\hline & $\mathrm{CAH}$ & Healthy reference Population & COPD \\
\hline $\mathrm{n}$ & 44 & 89 & 21 \\
\hline$\%$ male & 46 & 56 & 57 \\
\hline Mean age (SD) & $63(10.0)$ & $63(7.6)$ & $64(6.7)$ \\
\hline SIP Overall & $10.3(8.0-12.6)^{\bullet}$ & $2.2(1.5-3.0)$ & $10.6(7.4-13.8)$ \\
\hline Physical dimension & $11.6(8.0-15.3)^{\bullet}$ & $0.8(0.3-1.3)$ & $10.1(5.8-14.3)$ \\
\hline Ambulation & $19.3(14.6-24.0)^{\oplus}$ & $1.4(0.5-2.4)$ & $22.5(16.9-28.1)$ \\
\hline Body care/movement & $9.3(5.0-13.7)$ & $0.7(0.2-1.2)$ & $4.2(0.2-8.3)$ \\
\hline Mobility & $9.0(4.7-13.2)^{\top}$ & $0.4(0.0-1.0)$ & $11.8(5.5-18.1)$ \\
\hline Psychosocial dimension & $5.9(4.0-7.9)^{6}$ & $2.9(1.4-4.4)$ & $8.1(4.8-11.3)$ \\
\hline Emotional behaviour & $13.1(7.5-18.6)^{\oplus}$ & $3.7(1.9-5.5)$ & $8.1(3.6-12.7)$ \\
\hline Social interaction & $4.5(2.6-6.4)^{\#}$ & $2.8(1.5-4.2)$ & $12.3(7.3-17.4)$ \\
\hline Alertness behaviour & $4.4(2.0-6.9)$ & $2.9(0.8-5.0)$ & $3.6(0.2-6.9)$ \\
\hline Communication & $3.4(1.3-5.6)$ & $2.4(0.4-4.5)$ & $4.4(0.9-7.8)$ \\
\hline \multicolumn{4}{|l|}{ Free standing categories } \\
\hline Sleep/rest & $16.4(11.9-20.9)^{\bullet}$ & $5.9(4.0-7.8)$ & $13.4(9.0-17.8)$ \\
\hline Home management & $15.9(10.1-21.8)^{\bullet}$ & $0.9(0.2-1.7)$ & $23.9(15.2-32.6)$ \\
\hline Work & $27.3(17.4-37.1)^{\Phi \#}$ & $3.4(0.7-6.2)$ & $7.6(0.1-15.1)$ \\
\hline Recreation/pastimes & $13.9(8.3-19.5)^{9 \#}$ & $7.1(5.0-9.2)$ & $29.3(21.0-37.5)$ \\
\hline Eating & $2.2(0.9-3.5)^{9 \#}$ & $4.8(3.4-6.2)$ & $21.3(16.0-26.6)$ \\
\hline \multicolumn{4}{|l|}{ HAD } \\
\hline Anxiety & $6.6(5.0-8.1)^{\top}$ & $4.4(3.6-5.1)$ & $6.4(4.5-8.4)$ \\
\hline Depression & $3.7(2.8-4.6)$ & $3.3(2.7-3.8)$ & $5.3(3.9-6.7)$ \\
\hline MACL Overall & $3.06(2.91-3.21)^{\oplus}$ & $3.27(3.19-3.36)$ & $2.9(2.6-3.1)$ \\
\hline Pleasantness/unpleasantness & $3.17(3.00-3.34)$ & $3.30(3.20-3.40)$ & $2.9(2.6-3.1)$ \\
\hline Activation/deactivation & $2.95(2.79-3.12)^{\bullet}$ & $3.30(3.20-3.40)$ & $2.9(2.7-3.1)$ \\
\hline Calmness/tension & $3.05(2.88-3.22)$ & $3.21(3.09-3.34)$ & $2.9(2.6-3.2)$ \\
\hline
\end{tabular}

Data are presented as mean and 95\% confidence intervals for the mean are given in parentheses; data for Healthy References and for COPD-patients have by the courtesy of the authors, been extracted from reference [11]; ${ }^{\top}$ : significant $(\mathrm{p}<0.05)$ difference between chronic alveolar hypoventilation $(\mathrm{CAH})$ and Healthy subjects; ${ }^{\#}$ : significant $(\mathrm{p}<0.05)$ difference between $\mathrm{CAH}$ and COPD. 
dimension has been given a bipolar form. The patients indicate their current emotional state by marking a scale from 1-4. High scores indicate a positive emotional state. The scores of these dimensions may in turn be aggregated into an overall MACL score, which has been shown to be a good indicator of general wellbeing [24].

Global quality of life. The global quality of life rating was adopted from the European Organization for Research and Treatment of Cancer core Quality of Life Questionnaire QLQ-C30 [25] with a 1-7 response format from very poor to excellent.

To put the HRQL assessment in the patients studied into perspective, their results were compared to those of two populations, a health population and a sample of patients with chronic obstructive pulmonary disease (COPD) with similar age and forced expiratory volume in one second (FEV1) as the presently investigated patients. Data for these two comparison groups were taken from a previous publication by the present authors [11].

Statistical methods. Data are presented as means, 95\% confidence intervals for the mean, standard deviations (SD) and range.

Kruskal-Wallis nonparametric one way analysis of variance (ANOVA), was used to compare HRQL results between diagnostic subgroups. If significant, Fisher's nonparametric permutation test [26] was used post hoc for pairwise comparison.

For comparison between patients with $\mathrm{CAH}$ and healthy subjects or patients with COPD, Fisher's nonparametric permutation test was applied.

Pitman's nonparametric permutation test [26] was used to test associations between selected variables in groupings A-D (outcome variables) versus E (background variables): A) condition-specific complaints (sleep scale, breathlessness, SIP sleep/rest); B) functional health (overall SIP, SIP physical dimension, and SIP psychosocial dimension); C) mental health (overall MACL); D) overall quality of life (global quality of life rating); E) background variables (age, vital capacity, standard bicarbonate, morning arterial $P \mathrm{a}, \mathrm{CO}_{2}$, diagnostic groupings (TB sequelae versus all others and previous polio versus all others)).

The level of correlation was given by Pearson correlation coefficients. Independent predictors of the outcome variables were selected using Mantel's technique of pooling applied to Pitman's permutation test, a nonparametric partial correlation analysis. Multiple regression analysis was used to quantify the level of explained variances by the selected predictors.

All significance tests were two-tailed, with $\mathrm{p}<0.05$ taken as statistically significant.

\section{Results}

\section{Physiological measurements}

Lung function data and daytime and nocturnal blood gases showed values typical for patients with chronic alveolar hypoventilation due to neuromuscular or restrictive chest wall disorders (table 1).

\section{Social life}

Seventy per cent of the patients were married. Twenty-four per cent were gainfully employed and, of these, $90 \%$ were satisfied with their occupation. Satisfaction with relations and family members was reported as being $65 \%$. A good or very good economic situation was reported by $90 \%$ of the patients and $84 \%$ reported satisfactory leisure time.

\section{Health-related quality of life}

Breathlessness and sleep. Only five patients (11\%) reported breathlessness at rest. Thirty $(68 \%)$ patients reported breathlessness during ordinary walking. Sleep-related problems were frequent (fig. 1). The most common problems were difficulty in maintaining sleep (61\% of patients) and excessive daytime sleepiness (57\% of patients). Only $34 \%$ of the patients felt refreshed by sleep.

Functional health. The mean overall SIP score was high (10.3). The physical dimension was markedly affected with a mean score of 11.6, whereas the psychosocial dimension was only slightly affected. Most dysfunction, with mean scores $>10$, was found in the areas: ambulation, emotional behaviour, sleep/rest, home management, work and recreation/pastimes (table 3). Compared to published data from a healthy reference population [11] the study sample showed significantly more dysfunction in all SIP categories except for social

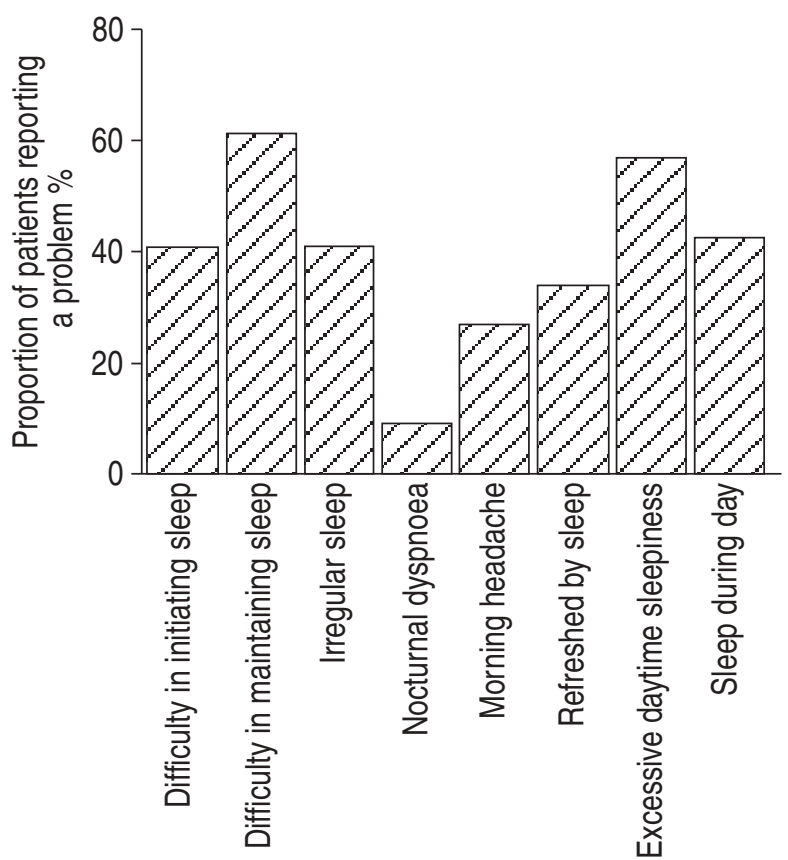

Fig. 1.- Sleep-related problems reported by the patients to occur once a week or always/almost always. Data are given as the proportion of patients reporting the problem. 
interaction, alertness behaviour, communication and eating (table 3 ).

Mental health. The HAD scores for anxiety and depression are shown in table 3 . Eleven per cent had scores between 8-10 (possible psychiatric morbidity) and $23 \%$ exceeded 10 points (probable pathological level of distress) on the HAD anxiety scale. The corresponding figures for the HAD depression scale, were 9 and $2 \%$, respectively. Mental wellbeing as measured by the overall MACL was on average 3.1, which is significantly less than in a healthy reference population (table 3 ).

Global quality of life. The global quality of life rating reached a mean value of 4.1 (range $2-7$ ) which is low compared to 5.2 in a general population [27].

Health-related quality of life by sex and age. There were no significant differences in HRQL between males and females. Age however, had an impact. Patients $>70$ yrs of age $(n=11)$, compared to those $<70$ yrs of age $(n=33)$, had significantly higher scores in Overall SIP (16.6 versus 10.1, SD 7.1 and 7.4), SIP physical dimension (19.1 versus 10.7, SD 10.2 and 11.2) and in the SIP categories sleep/rest (25.4 versus 13.3 , sD 19.5 and 13.3 ) and ambulation (27.5 versus 16.8, sD 7.0 and 16.3).

Health-related quality of life by underlying, diagnosis. Five out of 12 patients with previous polio, eight out of 11 patients with scoliosis and 16 out of 17 patients with TB sequelae reported breathlessness during walking. No patient with previous polio, one of 11 with scoliosis and four of 17 with TB sequelae reported breathlessness at rest. As the ANOVA results were nonsignificant, pairwise significance tests were not performed.

Functional health in the three major subgroups is illustrated in figures 2 and 3. A tendency for higher scores in patients with TB sequelae was observed in overall SIP, the two dimensions and the 12 categories (figs. 2 and 3). However, a significant difference was

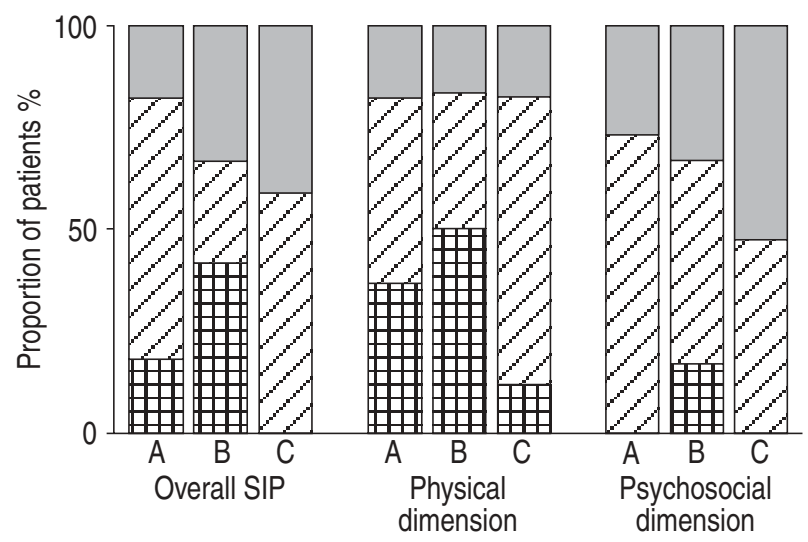

Fig. 2.-Proportion of patients with no dysfunction (Sickness Impact Profile (SIP) score=0; 囲), slight dysfunction (SIP score 010 ; $\mathbb{Z}$ ) or marked dysfunction (SIP score $>10$; $\square$ ) for the aggregated SIP dimensions in the three major diagnostic groups; scoliosis (A), previous polio (B), tuberculosis sequelae (C).

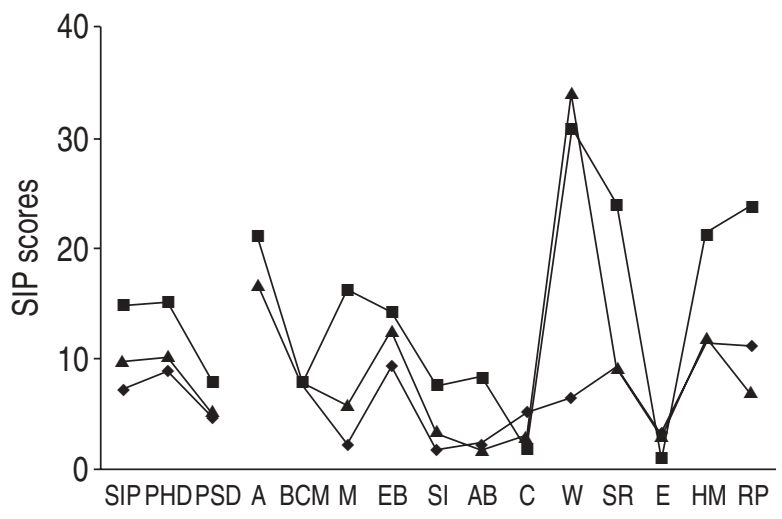

Fig. 3.-Mean Sickness Impact Profile (SIP) scores in the three major diagnostic groups: previous polio $(\checkmark)$; tuberculosis sequelae $(\boldsymbol{\square})$; and scoliosis $(\boldsymbol{\Delta})$. SIP: overall SIP; PHD: physical dimension; PSD: psychosocial dimension; A: ambulation; BCM: body care/movement; $\mathrm{M}$ : mobility; $\mathrm{EB}$ : emotional behaviour; SI: social interaction; $\mathrm{AB}$ : alertness behaviour; $\mathrm{C}$ : communication; W: work; SR: sleep/rest; E: eating; HM: home management; $\mathrm{RP}$ : recreation/pastimes.

seen only in the category sleep/rest, where patients with tb sequelae were more affected than both those with previous polio $(\mathrm{p}<0.01)$ and scoliosis $(\mathrm{p}<0.01)$.

Mental health as measured with MACL showed a significant difference $(\mathrm{p}<0.05)$ only in MACL activation/deactivation where patients with TB sequelae were more affected than those with previous polio (mean (95\% CI): 2.7 (2.5-3.0) versus 3.3 (3.0-3.6)). The distribution of patients with no, possible or probable pathological distress in the two HAD categories anxiety and depression was similar in the three major diagnostic groups. Patients with TB sequelae had a significantly lower $(\mathrm{p}<0.05)$ global quality of life than patients with previous polio (3.5, range 2-7 versus 4.9 , range $3-7$ ).

Correlation analyses between health-related quality of life and selected background variables. There were few significant correlations between background and outcome variables (table 4). Apart from age, which correlated with breathlessness $(r=0.50)$, SIP sleep/rest $(\mathrm{r}=0.29)$ and SIP psychosocial functioning $(\mathrm{r}=0.30)$, only one clinical measurement correlated with HRQL: standard bicarbonate concentration correlated with breathlessness $(\mathrm{r}=0.38)$ and SIP psychosocial functioning $(\mathrm{r}=0.30)$.

Partial correlation analysis showed that TB sequelae, age and standard bicarbonate were independent predictors of breathlessness (table 4). Tb sequelae versus all other diagnoses and previous polio versus all other diagnoses were equally strong predictors of SIP sleep/rest and global quality of life.

Multiple regression analysis of independent predictors (table 4) gave a range of $8-37 \%$ explained variance. Thirty seven per cent of the total variance in breathlessness was explained. Of SIP psychosocial dimension, $18 \%$ of the variance was explained. Relatively low levels of explained variance for other predictors were seen (data not shown). 
Table 4.-Relationships between selected background and outcome variables in patients with chronic alveolar hypoventilation $(n=44)$

Background variable

\begin{tabular}{lcccc}
\hline Outcome variable & Age & Standard bicarbonate & Polio/other & TB/other \\
\hline Breathlessness & 0.001 & 0.012 & $0.014^{\#}$ & 0.002 \\
Sleep Scale & $\mathrm{NS}$ & $\mathrm{NS}$ & 0.047 & $\mathrm{NS}$ \\
SIP sleep/rest & $0.045^{\#}$ & $\mathrm{NS}$ & 0.034 & 0.008 \\
Overall SIP & $\mathrm{NS}$ & $\mathrm{NS}$ & $\mathrm{NS}$ \\
SIP Physical dimension & $\mathrm{NS}$ & 0.014 & $\mathrm{NS}$ & $\mathrm{NS}$ \\
SIP Psychosocial dimension & 0.034 & $\mathrm{NS}$ & 0.017 & $\mathrm{NS}$ \\
Overall MACL & $\mathrm{NS}$ & $\mathrm{NS}$ & 0.040 & $\mathrm{NS}$ \\
Global QL & $\mathrm{NS}$ & $\mathrm{NS}$ & $\mathrm{NS}$ & 0.034 \\
\hline
\end{tabular}

P-values $(\mathrm{p}<0.05)$ from permutation tests are given. SIP: Sickness Impact Profile; MACL: Mood Adjective Check List; Global QL: global quality of life rating; ${ }^{\#}$ : nonsignificant after partial correlation, Mantel's test; NS: nonsignificant; TB: tuberculosis.

\section{Discussion}

The present study has shown that patients with $\mathrm{CAH}$ due to neuromuscular or restrictive chest wall disorders are affected in many vital areas of functional status, particularly those relating to physical activity. Compared to historical data from a healthy reference population [11], the patients studied here showed greater dysfunction in all SIP areas except social interaction, communication, alertness behaviour and eating (table 3). There were also significant differences in mental health (table 3). It thus seems clear that these patients have a severely impaired HRQL.

There are very few previous reports of HRQL in patients with CAH before treatment. MILler et al. [28] attempted to evaluate the influence of hypoventilation on HRQL in patients with Duchenne muscular dystrophy. Patients already receiving treatment were asked to report what they remembered about their quality of life and satisfaction with their vocation, education and recreation before treatment. The figures were then compared with what they felt at the time of investigation. Despite restrictions in daily life both before and after ventilator use, quality of life was considered fairly good. Except for this study, there are to the best of the authors' knowledge no publications on HRQL in untreated patients with CAH, so the present study adds new information of clinical value.

The limitations in several SIP categories, e.g. ambulation, home management and work are not surprising since several patients were physically handicapped due to their underlying disease. However, the marked dysfunction in SIP emotional behaviour cannot be easily predicted from the underlying diagnoses. This category contains items reflecting anxiety, irritation, low self-confidence, etc. In a previous study by PEHRSSON et al. [15], patients treated with home mechanical ventilation for $\mathrm{CAH}$ due to scoliosis, previous polio, TB sequelae or neuromuscular diseases showed only slight dysfunction (mean value 3.8 versus 13.7 in the present study) in emotional behaviour. The patients in the present study were not yet treated. It is therefore possible that chronic hypoventilation per se explains the pronounced dysfunction in emotional behaviour in these patients. Other psychosocial areas of the SIP, such as social interaction, alertness behaviour and communication were only slightly affected.

Sleep-related problems were common as indicated both by the sleep questionnaire and by the SIP sleep/ rest category (fig. 1 and table 3 ). These results are consistent with the general clinical impression that patients with CAH have major sleep disturbances.

The investigated population is heterogeneous since various underlying diseases can cause hypoventilation. Figures 2 and 3 indicate different HRQL patterns for patients with TB sequelae and previous polio. Although statistically significant differences appeared only in SIP sleep/rest, figures 2 and 3 suggest a pattern of differences in several additional functional health areas as well. The fact that patients with TB sequelae were older could have contributed to the observed differences between patients with TB sequelae and previous polio respectively. In the total study sample, patients aged $<>70$ yrs showed significant differences in the overall SIP, in SIP physical dimension and in the SIP categories sleep/rest and ambulation. Of 11 patients $>70$, six had TB sequelae while none had previous polio. It is known from other health status investigations that physical functioning slowly deteriorates with age and that there is a marked acceleration after 70 yrs of age [29]. The bivariate, partial and multiple correlations demonstrate the importance of both age and underlying diagnosis. Unfortunately the study sample was not big enough to make corrections for age in the different subgroups.

To put the present results into perspective, the study population was compared to a population of COPD patients with obstructive ventilatory impairment as well as a similar FEV1 [11]. Although the dysfunction profiles were similar (table 3) as well as the overall SIP and the SIP physical dimension, there were some distinct differences between patients with $\mathrm{CAH}$ and severe COPD. The patients studied here reported significantly more dysfunction in work and less dysfunction in social interaction and recreation/ pastimes than did those with COPD. Another clear and probably specific difference concerned eating behaviour, where CAH-patients did not show any dysfunction similar to COPD patients (table 3 ). This is in accordance with previous findings with regards 
malnutrition as a serious problem in the late stages of COPD [30] while it has not been identified as a major problem among patients with $\mathrm{CAH}$ due to neuromuscular or restrictive chest wall disorders. However, the authors conclusions are drawn with the reservation that comparisons have been performed with historical data and not data from individuals matched for age, sex and socioeconomic status.

The few correlations found between clinical observations (table 4) and HRQL measurements were weak or moderate $(r<0.50)$. This is in line with other studies of patients with chronic conditions, which repeatedly demonstrate a lack of association between clinical observations and HRQL variables, e.g. emotional wellbeing measurements [12, 13, 19]. Furthermore, it does not seem likely that concepts such as mental wellbeing or global quality of life could be explained in terms of lung function, blood gases or other surrogate measures. However, the correlations found between standard bicarbonate and breathlessness and SIP psychosocial functioning may reflect the impact of the hypoventilation per se. Further support for the connection between HRQL and degree of hypoventilation is the fact that low standard bicarbonate correlated with good mental wellbeing after noninvasive positive pressure ventilation (NIPPV) in the study by PEHrsson et al. [15].

Since chronic alveolar hypoventilation due to neuromuscular or restrictive chest disorders, is an uncommon condition, the authors consider the present study group to be relatively large. Nevertheless, the size of the sample was limited and the underlying diagnoses heterogeneous which hampers the analysis. Thus, the subgroups were too small to allow adjustments by e.g. age and sex. However, despite these limitations it was concluded that patients with chronic alveolar hypoventilation caused by neuromuscular or restrictive chest wall disorders have a severely impaired health-related quality of life, especially in areas of functional health. Age, the underlying disease and severity of hypoventilation, as measured by standard bicarbonate, relate to these health-related quality of life decrements. Well established self-assessment instruments that measure the various aspects of health-related quality of life can give a more comprehensive picture of the patient's situation.

Acknowledgements. The authors would like to thank N-G. Pehrsson for statistical guidance and A-M. Hilmersson and I-M. Doshe for collecting data. The authors also thank C.P. Engström and S. Larsson who kindly allowed use of their reference group for comparison with the present patients.

\section{References}

1. Martin TJ, Sanders MH. Chronic alveolar hypoventilation: a review for the clinician. Sleep 1995; 18: 617 634.

2. Carrol N, Branthwaite MA. Control of nocturnal hypoventilation by nasal intermittant positive pressure ventilation. Thorax 1988; 43: 349-353.
3. Sawicka EH, Loh L, Branthwaite MA. Domiciliary ventilatory support: an analysis of outcome. Thorax 1988; 43: 31-35.

4. Leger P, Bedicam JM, Cornette A, et al. Nasal intermittent positive pressure ventilation. Long-term follow-up in patients with severe chronic respiratory insufficiency. Chest 1994; 105: 100-105.

5. Lohr KN. Advances in health status assessment. Med Care 1989; 27: Suppl. S1-S294.

6. McSweeny AJ, Creer TL. Health-related quality-oflife assessment in medical care. Disease-a-Month 1995; 41: 1-72.

7. Spilker B. Quality of life and pharmacoeconomics in clinical trials. 2nd Edn. Philadelphia, LippincottRaven, 1996.

8. Gandek B, Ware JE. Translating functional health and well-being: International Quality of Life Assessment (IQOLA) Project studies of the SF-36 Health Survey. J Clin Epidemiol 1998; 51: 891-1214.

9. Sullivan M, Karlsson J, Taft C. How to assess quality of life in medicine: rationale and methods. In: GuyGrand B, Ailhaud G, eds. Progress in Obesity Research: 8. London, John Libbey, 1999; pp. 749755 .

10. Bergner M, Bobbit R, Carter W, Gilson B. The Sickness Impact Profile: development and final revision of a health status measure. Med Care 1981; 19: 787-805.

11. Engström CP, Persson LO, Larsson S, Ryden A, Sullivan M. Functional status and well being, in chronic obstructive pulmonary disease with regard to clinical parameters and smoking: a descriptive and comparative study. Thorax 1996; 51: 825-830.

12. Ahlmén M, Bengtsson C, Sullivan M, Bjelle A. A comparison of overall health between patients with rheumatoid arthritis and a population with and without rheumatoid arthritis. Scand $J$ Rheumatol 1990; 19: 413-421.

13. Sullivan $\mathbf{M}$, Ahlmén $M$, Bjelle A. Health status assessment in rheumatoid arthritis. 1. Further work on the validity of the Sickness Impact Profile. J Rheumatol 1990; 17: 439-447.

14. Bergman B, Sullivan M, Sörenson S. Quality of life during chemotherapy for small cell lung cancer. I. An evaluation with generic health measures. Acta Oncol 1991; 30: 947-957.

15. Pehrsson K, Olofson J, Larsson S, Sullivan M. Quality of life of patients treated by home mechanical ventilation due to restrictive ventilatory disorders. Respir Med 1994; 88: 21-26.

16. Bach JR, Campagnolo DI, Hoeman S. Life satisfaction of individuals with Duchenne muscular dystrophy using long-term mechanical ventilatory support. Am J Phys Med Rehabil 1991; 70: 129-135.

17. Quanjer PH, Tamnelung GJ, Cotes JE, et al. Lung volumes and forced ventilatory flows. Official statement of the European Respiratory Society. Eur Respir J 1993; 6: Suppl. 16, 5-40.

18. Sullivan M, Ahlmén M, Archenholtz B, Svensson G. Measuring health in rheumatic disorders by means of a Swedish version of the Sickness Impact Profile. Results from a population study. Scand J Reumatol 1986; 15: 193-200.

19. Lundqvist C, Sjösten A, Blomstrand C, Lind B, Sullivan M. Spinal cord injuries. Clinical, functional and emotional status. Spine 1991; 16: 78-83.

20. College of General Practitioners. Chronic bronchitis in Great Britain. BMJ 1961; ii: 973-979. 
21. Åkerstedt T, Torsvall L. Experimental changes in shift schedules: their effects on well-being. Ergonomics 1978; 21: 849-856.

22. Sullivan M. The Sickness Impact Profile (SIP): an instrument for overall health assessment, a basic evaluation. J Drug Ther Res 1988; 13: 167-169.

23. Zigmond A, Snaith R. The Hospital Anxiety and Depression scale. Acta Psychiatr Scand 1983; 67: 361370 .

24. Sjöberg L, Svensson E, Persson LO. The measurements of mood. Scand J Psychol 1979; 20: 1-18.

25. Aaronson NK, Ahmedzai S, Bergman B, et al. The European Organization for Research and Treatment of Cancer QLQ-C30: a quality-of-life instrument for use in international clinical trials in oncology. $J$ Natl Cancer Inst 1993; 85: 365-376.

26. Bradley J. Distribution-free statistical tests. London, Prentice Hall, 1968; pp. 68-86.
27. Hjermstad MJ, Fayers PM, Bjordal K, Kaasa S. Health-related quality of life in the general Norwegian population assessed by the European Organization for research and treatment of cancer core quality-of-life questionnaire: The QLQ=C30 (+3). J Clin Oncol 1998; 160: 1188-1196.

28. Miller JR, Colbert AP, Osber JS. Ventilator dependency: decision-making, daily functioning and quality of life for patients with Duchenne muscular dystrophy. Dev Med Child Neurol 1990; 32: 1078 1086.

29. Sullivan M, Karlsson J. The Swedish SF-36 Health Survey III. Evaluation of criterion-based validity: results from the normative population. J Clin Epidemiol 1998; 51: 1105-1113.

30. Wilson DO, Rogers RM, Wright EC. Body weight in chronic obstructive pulmonary disease. Am Rev Respir Dis 1989; 139: 1435-1438. 